\title{
Obtención de anticuerpos monoclonales de ratón contra proteasa de cisteína 5 recombinante de Entamoeba histolytica
}

\section{Production of monoclonal antibodies against cysteine protease 5 of Entamoeba histolytica}

\author{
Juanita Trejos S, ${ }^{1}$ M.Sc, Jhon Castaño O, ${ }^{1}$ Ph.D.
}

\begin{abstract}
${ }^{1}$ Universidad del Quindío. Facultad Ciencias de la Salud. Grupo Inmunología Molecular (GYMOL). Armenia, Colombia.*Correspondencia: jhoncarlos@uniquindio.edu.co
\end{abstract}

Recibido: Junio de 2010; Aceptado: Diciembre de 2011.

\section{RESUMEN}

Objetivo. Obtener anticuerpos monoclonales de ratón contra la proteasas de cisteína 5 (EhCP5) de Entamoeba histolytica. Materiales y métodos. Se inmunizaron ratones BALB/c por vía intraperitoneal con adyuvante de Freund completo e incompleto con la proteína recombinante EhCP5 obtenida a partir del cultivo de E.coli DH5a trasfectada con el vector recombinante pJC45 que expresa dicha proteína. Se seleccionó el animal con mejor respuesta de anticuerpos. Al cual se le extrajo su bazo como fuente de linfocitos $B$, los cuales se fusionaron utilizando PEG con células de mieloma de ratón SP2-0/Ag14. Se procedió a selección de los hibridomas y a la evaluación de los sobrenadantes de las colonias que crecieron a los 7 días mediante ELISA. Los hibridomas con valores más altos de anticuerpos específicos contra la proteína EhCP5r se seleccionaron, y los clones obtenidos por diluciones limitantes fueron expandidos. Resultados. A partir de un clon secretor estable se purifico el anticuerpo monoclonal anti EhCP5r del isotipo IgG1 por cromatografía de afinidad con proteína G. Los clones fueron expandidos in vivo e in vitro. Con el anticuerpo purificado se diseñaron tres sistemas de captura para evaluar la aplicabilidad del anticuerpo monoclonal anti EhCP5r como método inmunodiagnóstico. Conclusiones. Se logro la producción de un anticuerpo monoclonal específico contra EhCP5r que permite diferenciar Entamoeba histolytica de Entamoeba dispar.

Palabras clave: Anticuerpo, Entamoeba histolytica, , hibridoma, proteasas de cisteína, monoclonal, prueba ELISA (Fuentes:CAB, DeCS).

\begin{abstract}
Objective. Obtain mouse monoclonal antibodies against cysteine proteases 5 (EhCP5) of Entamoeba histolytica. Materials and methods. BALB/c mice were immunized intraperitoneally with complete and incomplete Freund adjuvant EhCP5 with the recombinant EhCP5 protein obtained from E.coli DH5a culture transfected with the recombinant vector pJC45 that expresses said protein. The animal with the best antibody response was selected. Its spleen was extracted as a source of B-lymphocytes, which were merged using PEG miceSP2-0/Ag14 myeloma cells. The team proceeded to undergo the selection of the hybridomas and the evaluation of the supernatants of the colonies that grew after 7
\end{abstract}


days by ELISA. The hybridomas with higher values of specific antibodies against the protein EhCP5r were selected, and clones obtained by limiting dilution were expanded Results. With the use of a stable secreting clone the monoclonal antibody anti EhCP5r IgG1 isotype was purified by affinity chromatography with protein G. The clones were expanded in vivo and in vitro. Three capture systems were designed with the purified antibody to assess the applicability of the monoclonal antibody anti EhCP5r as an immunodiagnostic method. Conclusions. The production of a specific monoclonal antibody against EhCP5r was achieved to differentiate Entamoeba histolytica from Entamoeba dispar.

Key words: Antibodies, cysteine proteases, entamoeba histolytica, enzyme-linked immunosorbent assay, hybridomas, monoclonal (Sources:CAB, DeCS).

\section{INTRODUCCIÓN}

Se calcula que el $10 \%$ de la población mundial está infectada por el complejo Entamoeba histolytica/dispar. Según la Organización Mundial de la Salud (OMS), hay 500 millones de nuevas infecciones (amebiasis) por año y aproximadamente 70.000 - 100.000 muertes. Al diferenciar estos datos, de los 500 millones de casos, el $90 \%$ presentan E. dispar y sólo el $10 \%$ E. histolytica, y de estos últimos, el $10 \%$ desarrollan amebiasis. A su vez esta patología sin el tratamiento adecuado da lugar a complicaciones potencialmente fatales (como absceso hepático, absceso cerebral, peritonitis, amebiasis mediastino-pericárdica y amebiasis pleuropulmonar), lo que representa un problema de salud pública (1-4).

En Colombia, entre 1977 y 1980 se realizó la segunda encuesta nacional de morbilidad en la cual la prevalencia del E. histolytica fue de $12.1 \%$ (5). En la población del municipio de Arboleda (Nariño) se encontró una prevalencia del complejo del $29.5 \%$, en un corregimiento del municipio de Santa Catalina, Bolivar del $54 \%$ (6) y en la ciudad de Armenia en asentamientos temporales post- terremoto, del $0.6 \%$ de E. histolytica (7). Aunque la distribución geográfica de ambas especies está todavía incompleta debido a que la metodología utilizada en la mayoría de los estudios no discriminan a ambas especies, es muy poco lo que se hace principalmente en los laboratorios clínicos de primer y segundo nivel para su diferenciación. Hecho por el cual se aumenta la tendencia a sobre-diagnosticar como amebiasis los síntomas gastrointestinales, sin confirmar su agente causal, problema, que entre otras consecuencias, conduce al uso innecesario de fármacos amebicidas, medicamentos agresivos que conllevan efectos secundarios.

La similitud morfológica de ambas especies impide la identificación del agente causal mediante exámenes coproparasitoscópicos directos y de concentración por flotación. La OMS y la Organización Panamericana de la Salud (OPS) sugieren que en el reporte microscópico debe anotarse "Complejo E. histolytica/E. dispar" y que el registro de $E$. histolytica sólo debe emplearse para la especie patógena, identificada por técnicas bioquímicas (zimodemos), de biología molecular, inmunológicas como los ensayos inmunoenzimáticos y cuando se observan trofozoítos con eritrocitos fagocitados. Los ensayos inmunoenzimáticos que se encuentran comercialmente, hasta el momento, para la determinación de E. histolytica, se fundamentan principalmente en el uso del anticuerpo monoclonal para la detección de la lectina Gal/GalNAc (8-10).

La cisteína proteasa 5 de E. histolytica (EhCP5), es un antígeno secretorio y uno de los factores de virulencia, que en los últimos años ha empezado a tener mayor importancia por su papel citopático y su participación en la inflamación y en la amebiasis invasiva. La ausencia de la EhCP5 en E. dispar, se considera de gran relevancia, pues se cree que es una de las principales causas para que esta especie no sea patógena (10-14).

El objetivo del presente trabajo fue obtener anticuerpos monoclonales de ratón para la detección de la EhCP5 y su posible uso como prueba diagnóstica y de diferenciación entre las especies $E$. histolytica y $E$. dispar, mediante una ELISA de captura.

\section{MATERIALES Y METODOS}

Animales de experimentación. En los esquemas de inmunización se utilizaron ratones BALB/c hembras, de 20 a 25 gramos de peso procedentes del bioterio central de la Universidad Nacional de Colombia y conejos Nueva Zelanda hembras de $2.5 \mathrm{~kg}$ de peso, 
los cuales se mantuvieron en condiciones adecuadas de alimentación y ciclo natural de luz y oscuridad.

Células. La línea celular de mieloma de ratón SP2/0-Ag14 (ATCC:CRL-1581) fue donada por el Lic. Ricardo Marcet del Instituto de Medicina Tropical Pedro Kouri de Cuba, la cual se mantuvo con medio DMEM (Invitrogen, USA), Antibiótico/Antimicótico (10.000 unidades/ml de penicilina, $19 \mathrm{ug} / \mathrm{ml}$ de gentamicina y 25 $\mathrm{ug} / \mathrm{ml}$ de anfotericina B), 1X (Sigma, USA), L-Glutamina 1X (Sigma USA), SFB (Invitrogen, USA) al $7 \%$ e incubado $37^{\circ} \mathrm{C}$ en $5 \%$ de $\mathrm{CO}_{2}$ en cajas de cultivo celular Nunc de $25 \mathrm{ml}$.

Parásitos y bacterias. La especie E. histolytica, cepa HM-1:IMSS (ATCC 30459) fue donada por el Dr. José Luis Rosales del Centro de Investigación y Estudios Avanzados (CINVESTAV) del IPN de México y el Dr. Rubén Santiago Nicholls del Instituto Nacional de Salud (INS) de Colombia. Los trofozoítos fueron cultivados axénicamente en el medio TYI-S-33 (15) en tubos tapa rosca e incubados a $37^{\circ} \mathrm{C}$ y subcultivados cada 48 a 72 horas, el cosechamiento se realizó durante la fase de crecimiento exponencial.

La especie E. dispar, cepa SAW 760 (ATCC 50484) fue gentilmente donada por la Dra. Consuelo López de la Facultad de Medicina de la Universidad Nacional de Colombia, sede Bogotá y fueron cultivados monoxénicamente en medio Robinson $(15,16)$ en tubos tapa rosca e incubados a $37^{\circ} \mathrm{C}$ y subcultivados cada 48 a 72 horas, el cosechamiento de los trofozoítos se realizó durante la fase de crecimiento exponencial.

Escherichia coli DH5a trasfectadas con el vector recombinante pJC45. La Dra. Iris Bruchhaus del Bernhard Nocht Institute for Tropical Medicine de Alemania gentilmente donó las células de Escherichia coli DH5a trasfectadas con el vector recombinante pJC45 con el gen de la proteína recombinante EhCP5, las cuales fueron mantenidas en medio de cultivo LuriaBertani suplementado con ampicilina $100 \mu \mathrm{g} / \mathrm{ml}$, kanamicina $50 \mu \mathrm{g} / \mathrm{ml}$ y glucosa $2 \%(\mathrm{p} / \mathrm{v})$, incubadas a $37^{\circ} \mathrm{C}$ hasta alcanzar una absorbancia de 0.4 a una densidad óptica de 600nm.

Obtención de proteína recombinante. La expresión de la EhCP5r por las bacterias transgenticas fue inducida por adición de isopropil$\beta$-D-tiogalactosidasa (IPTG) $0.1 \mathrm{mM}$ y el cultivo se continuó por $3 \mathrm{~h}$ más. Subsecuentemente el cultivo se centrifugó a $1200 \mathrm{rpm}$ por $15 \mathrm{~min}$ y el sobrenadante fue concentrado por evaporación a $37^{\circ} \mathrm{C}$ y se cuantificó la concentración de proteínas con el estuche comercial Bicinchoninic Acid Protein Assay Kit (BCA) de Sigma ${ }^{\circledR}$ siguiendo las indicaciones del fabricante.

La purificación de la proteína EhCP5r se llevó a cabo mediante elución pasiva a partir de la banda correspondiente a un peso molecular de $29 \mathrm{kDa}$ en la electroforesis en gel de poliacrilamida con dodecilsulfato de sodio (SDSPAGE, acrónimo en inglés de sodium dodecyl sulfate polyacrylamide gel electrophoresis) al $12 \%$ corrida en condiciones no denaturantes. Las bandas del gel se visualizaron mediante tinción inversa con imidazol $0.2 \mathrm{M}-\mathrm{SDS} 0.1 \%$ y sulfato de zinc $0.2 \mathrm{M}$. La elución de la proteína de la banda se realizó previa renaturalización del gel en solución salina tamponada con fosfato (PBS, acronimo en ingles dePhosphate Buffered Saline) - Triton $\times 100$ al $0.1 \mathrm{v} / \mathrm{v}$ (PBS-T) y lavado en PBS. La proteína fue eluida pasivamente por fragmentación de gel y resuspendida en PBS. La suspensión se sometió a agitación vigorosa, se incubó por $16 \mathrm{~h}$ a $4^{\circ} \mathrm{C}$ en esta solución y después se centrifugó por 60 minutos a $15.000 \mathrm{rpm} / 4^{\circ} \mathrm{C}$. Al sobrenadante se le determinó la concentración de proteínas con el estuche comercial BCA de Sigma ${ }^{\circledR}$.

Esquema de inmunización para la obtención de anticuerpos monoclonales anti EhCp5. Se realizaron esquemas de inmunización de 4 inoculaciones por ratón, por vía intraperitoneal a intervalos de 1 semana con la proteína EhCp5 recombinante a una concentración $1 \mathrm{mg}$ por animal. Las dos primeras con adyuvante completo de Freund (Sigma, USA) y las restantes con adyuvante incompleto de Freund (Sigma, USA). Las titulaciones de los sueros de los animales para la detección de anticuerpos contra EhCp5, se realizaron mediante ELISA indirecto especifico para $E$. histolytica. Al ratón con mayor titulo se le completó el esquema de inmunización con 2 dosis por vía intravenosa con $100 \mu \mathrm{g}$ de la proteína EhCp5 diluida en $100 \mu l$ de solución salina normal (SSN) estéril.

Igualmente se realizó un esquema de inmunización en conejos, consistente de 4 inoculaciones por conejo con la proteína EhCp5r a una concentración de $200 \mu \mathrm{g}$ por animal por vía intradérmica a intervalos semanales. Las dos primeras con adyuvante completo de Freund (Sigma, USA) y las restantes con adyuvante incompleto de Freund (Sigma, USA), y se completó el esquema con cinco inmunizaciones endovenosas cada dos días con $500 \mu$ de una solución de EhCp5r en SSN a una concentración de $100 \mu \mathrm{g}$. Las titulaciones de los sueros de los animales para la detección de anticuerpos contra EhCp5 se realizaron mediante un 
ensayo inmuno absorbente asociado a enzimas (ELISA, acrónimo en inglés de Enzyme-Linked Immunosorbent Assay) Indirecto especifico para E. histolytica.

Obtención de hibridomas. El animal con mas alto titulo de anticuerpos contra EhCp5, el cual recibió la inmunización endovenosa adicional fue sacrificado mediante sobredosis de anestésico y se le extrajo el bazo para utilizarse como fuente esplenocitos (linfocitos B) sensibilizados y se realizó la fusión con las células de mieloma de ratón SP2/0-Ag14 (ATCC:CRL-1581) para lo cual, se emplearon los procedimientos generales de la tecnología de obtención de hibridomas $(17,18)$, utilizando polietinelglicol (PEG-Sigma, USA) como agente de fusión. Los híbridos se cultivaron en medio de cultivo RPMI 1640 suplementado con medio Hypoxanthine Aminopterin Thymidine (HAT, Sigma, USA) como medio de selección metabólico. Los clonajes y reclonajes se realizaron por el método de dilución limitante. Se seleccionaron los clones productores de anticuerpos monoclonales anti EhCp5r y se criopreservaron con Dimetilsulfóxido al 10\% (DMSO Sigma USA) y almacenaron a $-80^{\circ} \mathrm{C}$.

Expansión in vivo. Se inmunosuprimieron 5 ratones BALB/C hembras multíparas con betametasona acetato/fosfato disódico 10X (Schering plough ${ }^{\circledR}$,Colombia) y a los dos días siguientes se inocularon introperitonealmente con $500 \mu \mathrm{l}$ de 2,6,10,14-tetrametil pentadecano (Pristane, Sigma USA), para diez días después, inocular intraperitonealmente, bajo técnicas de asepsia y antisepsia, $1.2 \times 10^{6}$ células de hibridomas/animal. Al cabo de 30 días post inoculación se pudo evidenciar el abultamiento del abdomen por la generación de ascitis en la cavidad peritoneal, el líquido ascítico se recolectó por punción intraperitoneal en tubos con anticoagulante EDTA y se almacenaron a $-20^{\circ} \mathrm{C}$ para luego purificar el anticuerpo monoclonal.

\footnotetext{
Purificación del líquido ascítico y sobrenadante de cultivo celular. La purificación de los anticuerpos monoclonales a partir de fluido ascítico y del sobrenadante se realizó por cromatografía de afinidad en una columna con proteína G Sepharosa CL 4B (GE Healthcare, Alemania), las muestras se diluyeron a partes iguales con tampón glicina $1.5 \mathrm{M}-\mathrm{NaCl} 3 \mathrm{M}$ pH 8.9 y se utilizó como solución de elución tampón de ácido cítrico 0.1 $\mathrm{M}$ a diferentes $\mathrm{pH}$ dependiendo de las subclases de IgG a purificar.
}

Se desalinizó por el método de HiTrap ${ }^{\mathrm{TM}}$ Desalting (GE Healthcare, USA), siguiendo las recomendaciones del fabricante. Se equilibró la columna prevista por el fabricante con tampón $\mathrm{NaCl} 25 \mathrm{mM}$, se aplicó la muestra (eluído de la cromatografía de afinidad a $\mathrm{pH}$ 6.0) y se recolectó la fracción eluída.

Sistema de ELISA para detección de anticuerpos anti EhCp5r. Para determinar los anticuerpos IgG séricos contra la proteína EhCP5r se desarrolló el siguiente ensayo inmunoenzimático indirecto: Se recubrieron los pozos de placas Maxisorp ${ }^{\mathrm{TM}}$ (Nunc, Suiza) con $100 \mu \mathrm{l}$ de solución de $3 \mu \mathrm{g} / \mathrm{ml}$ de la proteína recombinante, diluída en tampón de carbonato y bicarbonato $10 \mathrm{mM}$, pH 9.6 (Tampón de recubrimiento) y se incubaron a $37^{\circ} \mathrm{C}$ por 2 horas, al cabo de las cuales se lavaron 3 veces con PBS- Tween 20 al 0.5\% (PBS-T). Se realizó el bloqueo con $100 \mu$ lde tampón recubrimientoalbumina $2 \%$ incubado a temperatura ambiente durante toda la noche. Posteriormente se realizó nuevamente la fase de lavado y se adicionaron $100 \mu \mathrm{l}$ de las muestras (sueros) a una dilución de 1:200 en PBS-T. Se incubó en cámara húmeda a $37^{\circ} \mathrm{C}$ por 2 horas, al cabo de las cuales se realizaron lavados con PBS-T. Luego se adicionaron $100 \mu$ de solución de conjugado de anti-IgG de ratón unida a fosfatasa alcalina (Sigma, USA) a una dilución 1:2500 en PBS-T y se incubó a $37^{\circ} \mathrm{C}$ en cámara húmeda por 1 hora, luego se realizaron lavados y se adicionó substrato $p$-Nitrofenol fosfato ( $p$-NPP. Sigma, USA), la placa se incubó a $37^{\circ} \mathrm{C}$ en oscuridad, en cámara húmeda por 1 hora, la reacción se detuvo con $100 \mu \mathrm{l}$ de $\mathrm{NaOH}$ 1M. La lectura se realizó en el lector de microelisa marca DYNATECH MR 5000 a una longitud de onda de $410 \mathrm{~nm}$. Como controles para la titulación de anticuerpos de ratón se utilizaron, para el negativo una mezcla de sueros de cuatro ratones BALB/c sin inmunizar, y para el control positivo una mezcla de los sueros al día 28 post inoculación de los cuatro ratones inmunizados.

\footnotetext{
Ensayo inmunoenzimático indirecto para determinación de anticuerpos de conejo. Para determinar los anticuerpos IgG séricos contra la proteína EhCP5r se desarrolló el siguiente ensayo inmunoenzimático indirecto: Se recubrieron los pozos de placas Maxisorp ${ }^{\mathrm{TM}}$ (Nunc, Suiza) con $100 \mu$ de solución de 3 $\mu \mathrm{g} / \mathrm{ml}$ de la proteína recombinante, diluída en tampón de carbonato y bicarbonato 10 mM, pH 9.6 (Tampón de recubrimiento) y se incubaron a $37^{\circ} \mathrm{C}$ por 2 horas, al cabo de las cuales se lavaron 3 veces con PBS- Tween 20 al $0.5 \%$ (PBS-T). Se realizó el bloqueo con 100 $\mu$ l de Tampón de recubrimiento-Albumina $2 \%$
} 
incubado a temperatura ambiente durante toda la noche. Posteriormente se realizó nuevamente la fase de lavado y se adicionaron $100 \mu \mathrm{lde}$ las muestras (sueros) a una dilución de 1:200 en PBS-T. Se incubó en cámara húmeda a $37^{\circ} \mathrm{C}$ por 2 horas, al cabo de las cuales se realizaron lavados con PBS-T. Luego se adicionaron $100 \mu \mathrm{l}$ de solución de conjugado de anti-IgG de conejo unida a fosfatasa alcalina (Sigma, USA) a una dilución 1:2500 en PBS-T y se incubó a $37^{\circ} \mathrm{C}$ en cámara húmeda por 1 hora, luego se realizaron lavados y se adicionó substrato $p$-Nitrofenol fosfato ( $p$-NPP. Sigma, USA), la placa se incubó a $37^{\circ} \mathrm{C}$ en oscuridad, en cámara húmeda por 1 hora, la reacción se detuvo con $100 \mu$ lde $\mathrm{NaOH} 1 \mathrm{M}$. La lectura se realizó en el lector de microelisa marca DYNATECH MR 5000 a una longitud de onda de $410 \mathrm{~nm}$. Para la titulación de anticuerpos de conejo se utilizaron como control negativo el suero preinmune y como control positivo, el suero obtenido el día 28 post inmunización.

La cuantificación de la subclase de la IgG se hizo por el método del ácido bicinconinico (BCA acrónimo en inglés de bicinchoninic acid assay) (Sigma ${ }^{\circledR}$, USA) y como criterio de pureza se efectuó, mediante electroforesis según la metodología de Jevey González et al (19).

Evaluación del anticuerpo monoclonal hacia la EhCP5 frente a diferentes muestras. Se recubrieron los pozos de placas Maxisorp ${ }^{\text {TM }}$ (Nunc, Suiza) con $100 \mu$ de solución de $3 \mu \mathrm{g} / \mathrm{ml}$ de la proteína nativa y recombinante y sobrenadante del cultivo de trofozoítos de $E$. histolytica HM-1:IMSS, como control positivo y sobrenadante del cultivo de trofozoítos de $E$. dispar SAW 760, como control negativo, diluídos tanto las proteínas, como los sobrenadantes en tampón de recubrimiento carbonato bicarbonato $\mathrm{pH} 9.6$ y se incubaron a $37^{\circ} \mathrm{C}$ por 2 horas, se lavaron 3 veces con PBS- T al $0.5 \%$. Se realizó el bloqueo con $100 \mu \mathrm{l}$ de tampón de recubrimientoAlbumina $2 \%$ incubado a temperatura ambiente durante toda la noche. Posteriormente se realizó nuevamente la fase de lavado y se adicionaron $100 \mu \mathrm{l}$ del anticuerpo monoclonal (3G8C3) a una dilución de 1:200 en PBS-T. Se incubó en cámara húmeda a $37^{\circ} \mathrm{C}$ por 2 horas, al cabo de las cuales se realizaron lavados con PBS-T. Luego se adicionaron $100 \mu \mathrm{l}$ de solución de conjugado de anti-IgG de ratón unida a fosfatasa alcalina (Sigma, USA) a una dilución 1:2500 en PBS-T y se incubó a $37^{\circ} \mathrm{C}$ en cámara húmeda por 1 hora, luego se realizaron lavados y se adicionó substrato $\mathrm{p}$-NPP (Sigma, USA), la placa se incubó a $37^{\circ} \mathrm{C}$ en oscuridad, en cámara húmeda por 1 hora, la reacción se detuvo con $100 \mu \mathrm{l}$ de $\mathrm{NaOH}$ 1M. La lectura se realizó en el lector de microelisa marca DYNATECH MR 5000 a una longitud de onda de $410 \mathrm{~nm}$. Las proteínas y los controles se montaron por duplicado.

Inmunofluorescencia indirecta. Se utilizaron como muestras los trofozoítos cultivados de $E$. histolytica HM-1:IMSS, E. dispar SAW760 y un aislamiento clínico que se encontraba en proceso de análisis parasitológico en el Laboratorio del Centro de Investigaciones Biomédicas de la Universidad del Quindío, este aislamiento clínico hacia parte de las muestras recolectadas por estudiantes del programa de Biología, el cual contaba con su respectivo consentimiento informado para realizar pruebas de identificación.

Se agregaron $10 \mu \mathrm{l}$ de cada muestra a los pozos del portaobjeto para inmunofluorescencia, las muestras se fijaron con acetona por 3 minutos a $4^{\circ} \mathrm{C}$, se lavó el portaobjeto dos veces por 5 minutos con PBS- Albúmina 1\%. A continuación se agregó $10 \mu \mathrm{l}$ del anticuerpo monoclonal contra EhCP5r dilución 1:50 en PBS-Albumina $1 \%$ a cada pozo, se incubó en cámara húmeda durante 1 hora a $37^{\circ} \mathrm{C}$. Se repitieron los lavados con PBSAlbúmina $1 \%(\mathrm{v} / \mathrm{v})$. Se agregó el anticuerpo secundario (anti-IgG conjugado a FITC-SIGMA, USA) dilución $1: 100$ y se incubó durante 1 hora en cámara húmeda a $37^{\circ} \mathrm{C}$. Se lavó la placa cinco veces con PBS-Tween 20 al $0.05 \%(\mathrm{v} / \mathrm{v})$. Finalmente se observó cada uno de los pozos en microscopio de fluorescencia, objetivos $40 \mathrm{X}$ y 100X (Micromédica modelo BA2000i).

\section{RESULTADOS}

Expresión y purificación de la proteína recombinante EhCP5. Se logró la expresión y secreción de la proteína EhCp5 recombinante por las bacterias E.coli DH5 transgénicas mediante inducción con IPTG, demostrado por los valores obtenidos con la técnica de BCA de $1.2 \mathrm{mg} / \mathrm{ml}$ de proteína EhCP5r. Después de la elución pasiva, al sobrenadante se le cuantificó la concentración de la proteína EhCP5r, la cual fue de $347 \mu \mathrm{g} / \mathrm{ml}$.

Determinación de anticuerpos policlonales murinos contra EhCP5r. Los valores de los anticuerpos policlonales específicos (IgG) contra EhCP5r, presentes en el suero de los ratones BALB/c determinados por la densidad óptica (D.O) mediante ELISA, indicaron que el ratón con mayor valor sérico de anticuerpos policlonales específicos tipo IgG fue el ratón No. 2, con una D.O de 0.155 en el día 28 post inoculación, valor mucho mayor que el control negativo que tuvo una D.O de 0.030 , pero menor al control positivo con una D.O de 0.232 (Tabla 1). 
Tabla 1. Valores de anticuerpos específicos contra EhCP5r secretados por los hibridomas en el sobrenadante del cultivo celular determinados mediante ELISA indirecto.

\begin{tabular}{lccccccccc}
\hline & $\begin{array}{c}\text { Raton } \\
\text { 1 }\end{array}$ & $\mathbf{2}$ & $\mathbf{3}$ & $\mathbf{4}$ & $\begin{array}{c}\text { Raton } \\
\text { negativo } \\
\text { ratones }\end{array}$ & $\begin{array}{c}\text { Control } \\
\text { positivos }\end{array}$ & Conejo & $\begin{array}{c}\text { Control } \\
\text { negativo } \\
\text { conejo }\end{array}$ & $\begin{array}{c}\text { Control } \\
\text { positivo } \\
\text { conejo }\end{array}$ \\
\hline Día 0 & 0.013 & 0.062 & 0.035 & 0.016 & 0.03 & 0.232 & 0.032 & 0.038 & 0.903 \\
Día 7 & 0.039 & 0.091 & 0.055 & 0.033 & & 0.232 & 0.696 & & \\
Día 21 & 0.044 & 0.139 & 0.092 & 0.052 & & 0.232 & 1.484 & & \\
Día 28 & 0.055 & 0.155 & 0.105 & 0.068 & & 0.232 & 1.567 & & \\
Día 40 & & & & & & 1.648 & & \\
\hline
\end{tabular}

Determinación de anticuerpos policlonales de conejo contra EhCP5r. Los datos de la absorbancia de los sueros de los conejos inmunizados indicaron la presencia de anticuerpos policlonales específicos tipo IgG contra EhCP5r con un D.O de 1.648 en el día 40 post inoculación, el control negativo tuvo una D.O de 0.038 , y el control positivo una D.O de 0.903 (Tabla 1).

Clonación y reclonación por el método de dilución limitante. Después de 17 días de crecimiento se evaluaron 400 sobrenadantes de las colonias que crecieron en medio DMEM-HT, de los cuales se seleccionaron los hibridomas con valores más altos de anticuerpos específicos para EhCP5r, obteniendo 24 hibridomas secretores, los cuales tuvieron valores de D.O de 0.847 a 1.699 (Figura 1). Después de 10 días de cultivo, en 5 de los 24 pozos sembrados el crecimiento presentó las características fenotípicas de estos hibridomas, los cuales fueron evaluados obteniendo 4 hibridomas estables secretores de anticuerpos específicos anti EhCp5 (Figura 1). Con base en estos resultados se seleccionaron los hibridomas 1D3D1 (D.O 1.700), 3G8C3 (D.O 1.736) y 5G7A6 (D.O 1.685), a los cuales se les realizó la clonación y reclonación por dilución limitante.

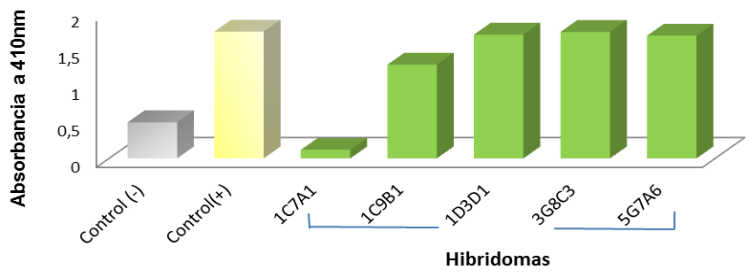

Figura 1. Valores de anticuerpos anti EhCP5 en D.O a una longitud de onda de $410 \mathrm{~nm}$ de los sobrenadantes de los hibridomas obtenidos y su comparación con los controles positivos y negativos.

A partir del crecimiento que presentaron los hibridomas en las placas después de la clonación y reclonación se seleccionó el clon 3G8C3 secretor del anticuerpo monoclonal anti EhCP5r para la expansión in vitro e in vivo, debido a que presentó durante todo el proceso altos niveles de secreción del anticuerpo y tuvo un crecimiento característico de este tipo de hibridomas. El clon 3G8C3 que se expandió a cajas de $125 \mathrm{ml}$ mantuvo su capacidad secretora de anticuerpos y produjo una ascitis marcada en las hembras de ratones BALB/C inoculadas, máxima a los 20 días.

\section{Purificación del líquido ascítico y} sobrenadante de cultivo celular. Se logró purificar el anticuerpo monoclonal, presentándose un único pico cromatográfico al eluír la columna con ácido cítrico $0.1 \mathrm{M}$ a $\mathrm{pH}$ 6.0, por lo que se pudo determinar que el anticuerpo monoclonal anti-EhCP5r es una inmunoglobulina $\mathrm{G}$ subclase $1\left(\mathrm{IgG}_{1}\right)$.

La cuantificación de la subclase $\mathrm{IgG}_{1}$ mediante el método de BCA dio un valor de $279.4 \mu \mathrm{g} / \mathrm{ml}$ de proteína purificada.

\section{Determinación de la capacidad de reconocimiento del anticuerpo monoclonal contra EhCP5 utilizando diferentes} muestras. Se compararon las D.O obtenidas mediante ELISA del anticuerpo monoclonal anti EhCP5 al reaccionar contra la proteína nativa purificada (D.O 0.367) y de la proteína recombinante (D.O 0.445), asimismo los valores para los sobrenadantes de las amebas HM-1:IMSS (D.O 0.484) y SAW760 (D.O 0.206) mantenidas en cultivo.

Inmunofluorescencia indirecta. Se pudo observar un resultado positivo en los trofozoítos de E. histolytica HM-1:IMSS marcados con el anticuerpo monoclonal anti EhCP5r (Figura $2 \mathrm{~A}$,

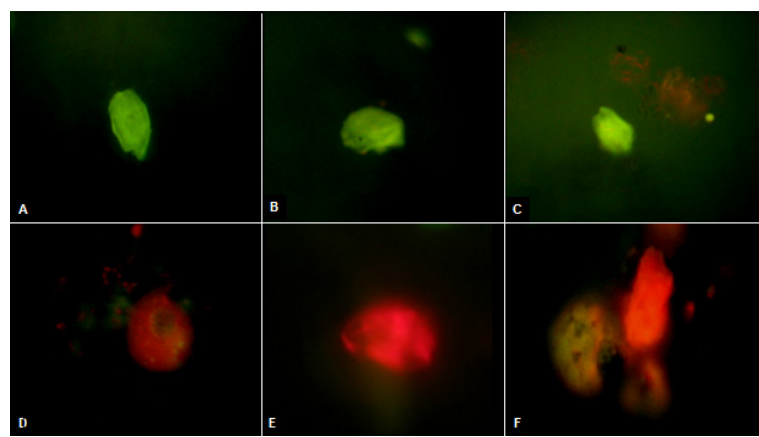

Figura 2. Inmunofluorescencia indirecta de trofozoitos de entamoeba utilizando los anticuerpo monoclonales obtenidos: A y B: Entamoeba histolytica HM-1:IMSS reconocida por el anticuerpo monoclonal anti-EhCP5r. C: Entamoeba histolytica (Verde) y Entamoeba dispar (rojo). Protozoos presentes en un aislamiento clínico. D, E, F: Entamoeba dispar SAW760 no reconocida por el anticuerpo monoclonal anti-EhCP5r. 
B), mientras que el resultado fue negativo en los trofozoítos de E. dispar SAW760 (Figura 2 $D, E, F)$. En el aislamiento clínico se observaron resultados positivos y negativos sugiriendo la presencia de trofozoítos de E. histolytica y de $E$. dispar (coinfección) (Figura 2 C).

\section{DISCUSIÓN}

La diferenciación de E. histolytica de E. dispar continúa siendo un problema en el diagnóstico rutinario a pesar de las diferentes técnicas que se han desarrollado a nivel de inmunoanálisis, bioquímica y biología molecular para realizar una rápida identificación de $E$. histolytica. Algunos sistemas de detección de proteínas que actúan como factores de virulencia de $E$. histolytica y en los que se utilizan anticuerpos monoclonales para la diferenciación de especie son: E. histolytica test II (TechLab, Blacksburg, Va), el cual está diseñado con un anticuerpo monoclonal de segunda generación anti Lectina Gal/GalNAc y el ensayo inmunoenzimático ENZYMEBA (desarrollado en el Instituto de Medicina Tropical "Pedro Kourí" de Cuba) donde se utilizó un anticuerpo monoclonal de primera generación contra la proteína histolísaina, asimismo se han desarrollado otros métodos de ELISA que han permitido la diferenciación de la Entamoeba a nivel de especie (20-24).

Muchos otros anticuerpos monoclonales contra proteína de $E$. histolytica han sido diseñados específicamente para estudios de morfología y caracterización de enzimas y otras proteínas involucradas en el metabolismo de este protozoo, además de la patofisiología de la amebiasis o como posibles candidatos terapéuticos $(9,25)$.

Se han realizado múltiples estudios de cisteínas proteasas de los protozoos por ser consideradas factores de virulencia no sólo en $E$. histolytica (EhCP1, EhCP2, EhCP5 y EhCP112) sino también en otros protozoos como Leishmania mexicana (Imcpa, Imcpb y Imcpc), Leishmania L.chagasi (Ldccys1) Trichomonas vaginalis (CP30 y CP65), Trypanosoma cruzi (cruzipaína 1) y Plasmodium falciparum (falcipaína 2). Algunas investigaciones sobre estas proteasas han requerido la realización de anticuerpos policlonales y monoclonales de primera y segunda generación para determinar su localización y características funcionales, además de generar perspectivas del uso de estas enzimas como candidatos vacunales (14,26-27).

El objetivo de obtener anticuerpos monoclonales murinos que reconocieran la proteína EhCP5r para diferenciar E. histolytica de E. dispar por medio de un ensayo inmunoenzimático indirecto, se basó en la información obtenida por múltiples estudios, donde demostraron que el gen EdCP5 presenta diferencias de hasta un $20 \%$ en su secuencia de nucleótidos con el gen EhCP5, incluyendo deleciones e inserciones que producen múltiples codones de paro dentro del marco de lectura, dañando la funcionalidad del gen, presentándose un fenotipo de E. dispar que no puede expresar la proteína, y de ésta manera el anticuerpo contra EhCP5r no encuentra una secuencia homóloga proteica que reconocer en la muestras, hecho que podría explicar los resultados obtenidos en las pruebas inmunológicas realizadas para evaluar el anticuerpo monoclonal como la inmunofluorescencia indirecta (Figura 2) y los ensayos inmunoenzimáticos indirectos $(13,28,29)$.

La estabilidad genética de los hibridomas en cultivo depende de factores tan sensibles como el pH del medio de cultivo y la disponibilidad de nutrientes esenciales y como consecuencia de la adaptación a estas condiciones algunos hibridomas pierden cromosomas, presentándose la perdida de la capacidad de secreción de anticuerpos o de sus funciones básicas para la viabilidad celular. Para evitar la multiplicación de estos híbridos no secretores de anticuerpos, los cuales por ser metabólicamente más eficientes podría dominar el cultivo, inmediatamente después de evaluar los sobrenadantes de las colonias se procedió al proceso de clonación y reclonación. Este proceso además fue de gran importancia debido a que la población de hibridomas obtenida después de la fusión fue heterogénea con relación a los anticuerpos secretados por ella y se precisó seleccionar los híbridos productores del anticuerpo específico de interés, asegurando que las inmunoglobulinas secretadas por el cultivo fueran idénticas y así cerciorar la estabilidad y el carácter monoclonal del mismo lo que permitió al final de esta etapa seleccionar un único clon secretor (3G8C3) del anticuerpo específico contra EhCP5r $(17,18,30-32)$.

La determinación de la capacidad de reconocimiento del anticuerpo monoclonal contra EhCP5 utilizando diferentes muestras permitió observar valores superiores para la proteína nativa secretada por la cepa HM-1:IMSS en el medio de cultivo. Este resultado es de gran relevancia, pues la inducción de la inmunidad especifica en los ratones para la obtención del anticuerpo monoclonal se realizó con la proteína recombinante EhCP5, la cual mediante los ensayos de zimografía evidenció que mantiene 
su actividad de proteasa, y finalmente con este resultado de reconocimiento inmune, se puede asumir que los determinantes antigénicos de esta cisteína proteasa recombinante también se mantienen íntegros, lo cual permite entonces utilizar el anticuerpo monoclonal obtenido para la determinación de esta importante enzima en muestras clínicas positivas para el complejo $E$. histolytica/E. dispar.

Es de considerar que si bien $E$. dispar no expresa la cisteína proteasa 5 (CP5), esta ameba produce otra serie de cisteína proteasas como la CP1, CP2, CP3 y CP8, las que muestran grados diversos de homología con la EhCP5 (33-36). Lo anterior podría explicar los valores de absorbancia obtenidos con el sobrenadante del cultivo de la cepa SAW760, sin embargo los valores de D.O obtenidos contra la cepa de $E$. dispar SAW760 son inferiores a los obtenidos contra la cepa de E. histolytica HM-1:IMSS y permitió diferenciar una especie de otra.

Por lo anterior y con base en los resultados observados en los ensayos realizados y en la información que brinda la literatura científica hasta el momento sobre EhCP5, podría ser posible el uso del anticuerpo monoclonal anti - EhCP5r para ser utilizado en una prueba diagnóstica para diferenciar $E$. histolytica de $E$. dispar.

En el presente estudio se logró obtener un anticuerpo monoclonal de ratón que reconoce la proteína cisteína proteasa 5 recombinante de E. histolytica (EhCP5r), capaz de reconocer tanto en la prueba de ELISA como en la Inmunofluorescencia la cisteína proteasa 5 de $E$. histolytica nativa y recombinante. Es necesario realizar ensayos de validación de las técnicas inmunodiagnóstica para diferenciación de E. histolytica de E. dispar con muestras coprológicas, y sería conveniente utilizar el anticuerpo monoclonal obtenido para determinar la importancia de la cisteína proteasa 5 de E. histolytica en los diferentes procesos fisiopatogénicos de este protozoo.

\section{Agradecimientos}

A la Maestría en Ciencias Biomédicas de la Universidad del Quindío que financió la realización del presente trabajo.

\section{REFERENCIAS}

1. Samie A, Obi L, Bessong P, Stroup S, Houpt, Guerrant R. Prevalence and species distribution of $E$. histolytica and $E$. dispar in the venda region, limpopo, South Africa. Am J Trop Med Hyg 2006; 75:565-71.

2. Amin J. Seasonal prevalence of intestinal parasites in the United States. J Trop Med Hyg 2000; 66: 799-803.

3. Haque R, Petri WA. Diagnosis of amebiasis in Bangladesh. Arch Med Res 2006; 37:273-6.

4. Mora L, García A, De Donato M. Prevalencia del complejo Entamoeba histolytica/ Entamoeba dispar en pacientes con síntomas gastrointestinales de diarrea procedentes de Cumaná, Estado Sucre. Kasmera 2005; 33:36-45.

5. Botero D, Restrepo M. Parasitosis humanas. 4ta ed. Medellín: Corporación para Investigaciones Biológicas, CIB; 2003.
6. Agudelo-Lopez $S$, Gómez-Rodríguez L, Coronado X, Orozco A, Valencia-Gutierrez C, Restrepo-Betancur $L$ et al. Prevalencia de parasitosis intestinales y factores asociados en un corregimientode la Costa Atlántica Colombiana. Rev Salud Pública 2008; 10:633-42.

7. Gallego ML, Gómez-Marín JE, Torres E, Lora F. Prevalencia de Entamoeba histolytica en asentamientos temporales post-terremoto de la ciudad de Armenia. Infectio 2003; 7:190-94.

8. Tanyuksel M, Petri WA Jr. Laboratory diagnosis of amebiasis. Clin Microbiol Rev 2003; 16:713-29.

9. Fonte-Galindo L. Amebiasis: enfoques actuales sobre su diagnóstico, tratamiento y control. La Habana Cuba: Editorial Elfos Scientae; 2000. 
10. Fotedar R, Stark D, Beebe N, Marriott D, Ellis J, Harkness J. Laboratory Diagnostic Techniques for Entamoeba Species. Clin Microbiol Rev 2007; 20:511-32.

11. Espinosa-Cantellano ME, Martínez-Palomo AM. Pathogenesis of intestinal amebiasis: from molecules to disease. Clin Microbiol Rev 2000; 13:318-31.

12. Coudrier $\mathrm{E}$, Amblard F, Zimmer C, Roux $\mathrm{P}$, Olivo-Marin JC, Rigothier MC, et al. Myosin II and the Gal-GalNAc lectin play a crucial role in tissue invasion by Entamoeba histolytica. Cell Microbiol 2005; 7:19-27.

13. Tillack $M$, Nowak N, Lotter $H$, Bracha $R$, Mirelman D, Tannich $\mathrm{E}$, et al. Increased expression of the major cysteine proteinases by stable episomal transfection underlines the important role of EhCP5 for the pathogenicity of Entamoeba histolytica. Mol Biochem Parasitol 2006; 149:58-64.

14. Singh A, Houpt E, Petri WA.Rapid Diagnosis of Intestinal Parasitic Protozoa, with a Focus on Entamoeba histolytica. Interdiscip Perspect Infect Dis 2009; 2009:547090.

15. Clark CG, Diamond LS. Methods for cultivationof luminal parasitic protists of clinical importance. Clin Microbiol Rev 2002; 15:329-41.

16. Vázquez-Echeverría $\mathrm{Cl}$, Zavala $\mathrm{Gl}$, Chávez $\mathrm{B}$, Echeverría-Martínez OM, Vázquez-Nin $\mathrm{GH}$, Segura-Valdez MLs, et al. Evidencia ultraestructural del nucléolo de Entamoeba histolytica. Tip Revista Especializada en Ciencias Químico-Biológicas 2009; 12:34-37.

17. Shire SJ, Gombotz W, Bechtold-Peters K, Andya J. Current Trends in Monoclonal Antibody Development and Manufacturing. New York: American Association of Pharmaceutical Scientists; 2010.

18. Machado NP, Téllez GA, Castaño JC. Anticuerpos monoclonales:desarrollo físico y perspectivas terapéutica. Infectio 2006; 10:186-19.

19. Jevey-González A, Hernández-González SM, Nápoles-Vega A, Pedrosa-Amado A, Ramírez-Zayas R. Obtención, purificación y caracterización de IgG policlonal de conejo anti-Lipoproteína (A) humana. Archivo Médico de Camagüey 2005; 9:1-10.
20. Haque R, Mollah NU, Ali IK, Alam K, Eubanks $A$, Lyerly $D$, et al. Diagnosis of amebic liver abscess and intestinal infection with the TechLab Entamoeba histolytica II antigen detection and antibody tests. J Clin Microbiol 2000; 38:3235-9.

21. Haghighi A, Rezaeian M. Detection of serum antibody to Entameba histolytica in various population samples of amebic infection using an enzyme-linked immunosorbent assay. Parasitol Res 2005; 97:209-12.

22. Pillai DR, Kain KC. Recent developments in amoebiasis:the Gal/GalNAc lectins of Entamoeba histolytica and Entamoeba dispar. Microbes Infect 2000; 2:1775-83

23. Zeehaida M, Wan Nor Amilah WA, Amry AR, Hassan S, Sarimah A, Rahmah N.A study on the usefulness of Techlab Entamoeba histolytica II antigen detection ELISA in the diagnosis of amoebic liver abscess (ALA) at Hospital Universiti Sains Malaysia (HUSM), Kelantan, Malaysia. Trop Biomed 2008; 25:209-16.

24. Haghighi A, Rezaeian M.Detection of serum antibody to Entameba histolytica in various population samples of amebic infection using an enzyme-linked immunosorbent assay. Parasitol Res 2005; 97:209-12.

25. Reyes L, León R. Diferenciación de Entamoeba histolytica/Entamoeba dispar y los nuevos hallazgos en la patogénesis de la amebiasis intestinal. Rev Costarric Cienc Méd 2002; 23:161-73.

26. Klemba M, Goldberg DE. Biological roles of proteases in parasitic protozoa. Annu Rev Biochem 2002; 71:275-305.

27. Ferreira JH, Gentil LG, Dias SS, Fedeli CE, Katz S, Barbiéri CL. Immunization with the cysteine proteinase Ldccys1 gene from Leishmania (Leishmania) chagasi and the recombinant Ldccys1 protein elicits protective immune responses in a murine model of visceral leishmaniasis. Vaccine 2008; 26:677-85.

28. Que X, Reed SL. Cysteine proteinases and the pathogenesis of amebiasis. Clin Microbiol Rev 2000; 13:196-206. 
29. QueX, Brinen LS, Perkins $P$, Herdman $S$, Hirata $\mathrm{K}$, Torian BE, et al. Cysteine proteinases from distinct cellular compartments are recruited to phagocytic vesicles by Entamoeba histolytica. Mol Biochem Parasitol 2002; 119:23-32.

30. Que X, Kim SH, Sajid M, Eckmann L, Dinarello CA, McKerrow JH, et al. A surface amebic cysteine proteinase inactivates interleukin-18. Infect Immun 2003; 71:1274-80.

31. Yang ST, Luo J, Chen C. A fibrous-bed bioreactor for continuous production of monoclonal antibody by hybridoma. Adv Biochem Eng Biotechnol 2004; 87:61-96.

32. Müthing J, Kemminer SE, Conradt HS, Sagi $D$, Nimtz M, Kärst $U$, et al. Effects of buffering conditions and culture $\mathrm{pH}$ on production rates and glycosylation of clinical phase I antimelanoma mouse IgG3 monoclonal antibody R24. Biotechnol Bioeng 2003; 83:321-34.

33. Gómez-Marín JE. Protozoología médica. Protozoos parásitos en el contexto latinoamericano. Bogotá, Colombia: Manual Moderno Ltda; 2010.
34. Bruchhaus I, Loftus BJ, Hall N, Tannich E. The intestinal protozoan parasite Entamoeba histolytica contains 20 cysteine protease genes, of which only a small subset is expressed during in vitro cultivation. Eukaryotic Cell 2003; 2:501-9.

35. Meléndez-López SG, Herdman S, Hirata K, Choi MH, Choe Y, Craik C, et al. Use of recombinant Entamoeba histolytica cysteine proteinase 1 to identify a potent inhibitor of amebic invasion in a human colonic model. Eukaryot Cell 2007; 6:1130-6.

36. Willhoeft U, Hamann L, Tannich E. A DNA Sequence corresponding to the gene encoding Cysteine Proteinase 5 in Entamoeba histolytica is present and positionally conserved but highly degenerated in Entamoeba dispar. Infect Immun 1999; 67:5925-9. 